\title{
Modeling of Shock Tunnel Aeroheating Data on the Mars Science Laboratory Aeroshell
}

\author{
Michael J. Wright, ${ }^{*}$ Joe Olejniczak, ${ }^{*}$ and James L. Brown* \\ NASA Ames Research Center, Moffett Field, California 94035 \\ Hans G. Hornung ${ }^{\dagger}$ \\ California Institute of Technology, Pasadena, California 91125 \\ and \\ Karl T. Edquist ${ }^{\ddagger}$ \\ NASA Langley Research Center, Hampton, Virginia 23681 \\ DOI: $10.2514 / 1.19896$
}

\begin{abstract}
A series of shots are run in the $T 5$ shock tunnel at California Institute of Technology to measure heating levels on a 70 blunt cone at angle of attack in an environment representative of the Mars Science Laboratory entry. Twenty shots are obtained in $\mathrm{CO}_{2}$ over a range of enthalpies and pressures chosen to span the laminar and turbulent flow regimes. The data indicate that the lee side turbulent heating augmentation predicted by flight simulations is valid and must be accounted for during the design of the thermal protection system. Computational fluid dynamic simulations are generally in good agreement with the laminar data when employing a supercatalytic wall model, whereas turbulent simulations are in reasonable agreement when a noncatalytic wall model is used. The reasons for this discrepancy are unknown at this time. The turbulent heating augmentation is shown to be inversely related to freestream enthalpy. Changes in angle of attack between 11 and 16 are shown to have minimal impact on measured and computed heating. A transition criterion based on momentum thickness Reynolds number, analogous to that used in flight predictions, predicts onset with reasonable accuracy, although transition is observed to occur later than the current design criterion indicates.
\end{abstract}

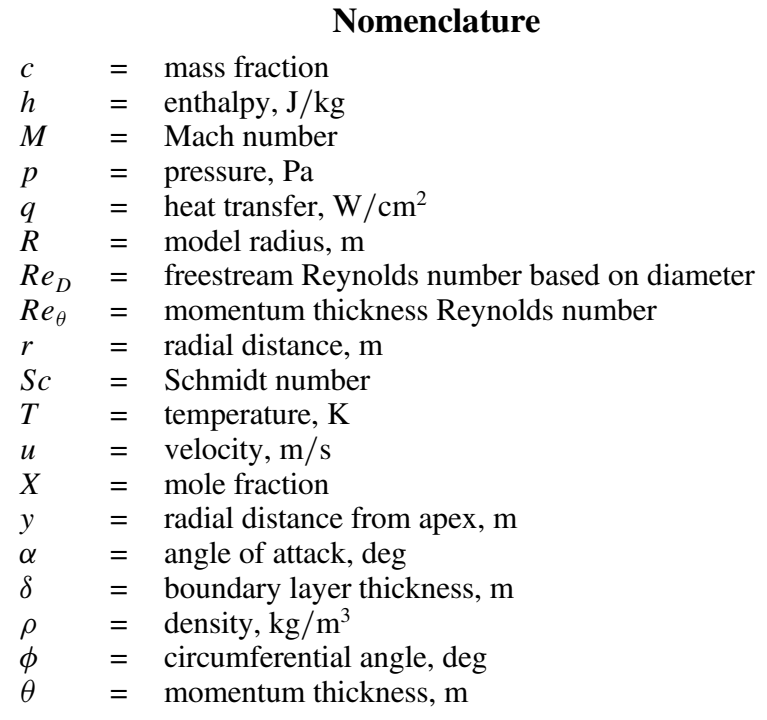

Subscripts

Presented as Paper 0177 at the 43rd Aerospace Sciences Meeting and Exhibit, Reno, NV, 10-13 January 2005; received 5 September 2005; revision received 13 November 2005; accepted for publication 16 November 2005. This material is declared a work of the U.S. Government and is not subject to copyright protection in the United States. Copies of this paper may be made for personal or internal use, on condition that the copier pay the $\$ 10.00$ per-copy fee to the Copyright Clearance Center, Inc., 222 Rosewood Drive, Danvers, MA 01923; include the code $\$ 10.00$ in correspondence with the CCC.

${ }^{*}$ Senior Research Scientist, Reacting Flow Environments Branch, MS 2302. Senior Member AIAA.

${ }^{\dagger}$ Kelly Johnson Professor of Aeronautics, Graduate Aeronautical Laboratories. AIAA Fellow.

¥Aerospace Engineer, Exploration Systems Engineering Branch, MS 365 . Senior Member AIAA.

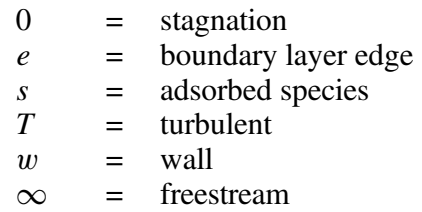

\section{Introduction}

$\mathbf{T}$ HE Mars Science Laboratory (MSL) is currently scheduled for launch in 2009. The program is considering a lifting entry vehicle (as opposed to the ballistic entries of Pathfinder and MER) to enable greater flexibility in landing site selection (via increased altitude and/or latitude capability) and improved accuracy in the final landing ellipse. The nominal configuration at this time consists of a $3.75 \mathrm{~m}$ diam 70 sphere cone, which will enter the Martian atmosphere at $11 \mathrm{deg}$ angle of attack to generate a lift to drag ratio of approximately 0.18 . The diameter and angle of attack of the proposed MSL vehicle are similar to that of the Viking landers, but the entry velocity will be considerably larger ( $\sim 5.8 \mathrm{vs} 4.6 \mathrm{~km} / \mathrm{s})$ since the Viking landers entered from Mars orbit in an attempt to reduce the severity of the entry heating environment [1]. The combination of large size and relatively high entry velocity makes transition to turbulence and the resultant turbulent heating levels much more serious concerns than for previous Martian entries. Earlier studies [2] have demonstrated that standard turbulence models predict turbulent heating levels on the lee side of the forebody that greatly exceed stagnation point heating rate. In addition, design correlations indicate that transition will occur in flight before the peak heating point on the trajectory [2]. Figure 1 shows the computed laminar and turbulent heating rates for the peak heating point of a representative MSL trajectory

$\left(u_{\infty}=5.33 \mathrm{~km} / \mathrm{s}, \rho_{\infty}=5.095 \times 10^{-4} \mathrm{~kg} / \mathrm{m}^{3}, \alpha=11 \mathrm{deg}\right)$. The turbulent simulation predicts a heat flux on the lee side of the cone in excess of $120 \mathrm{~W} / \mathrm{cm}^{2}$, which is more than twice as high as the laminar heating rate at the cone apex. If these computational predictions are accurate, the forebody thermal protection system (TPS) of the MSL mission will be sized according to the turbulent 


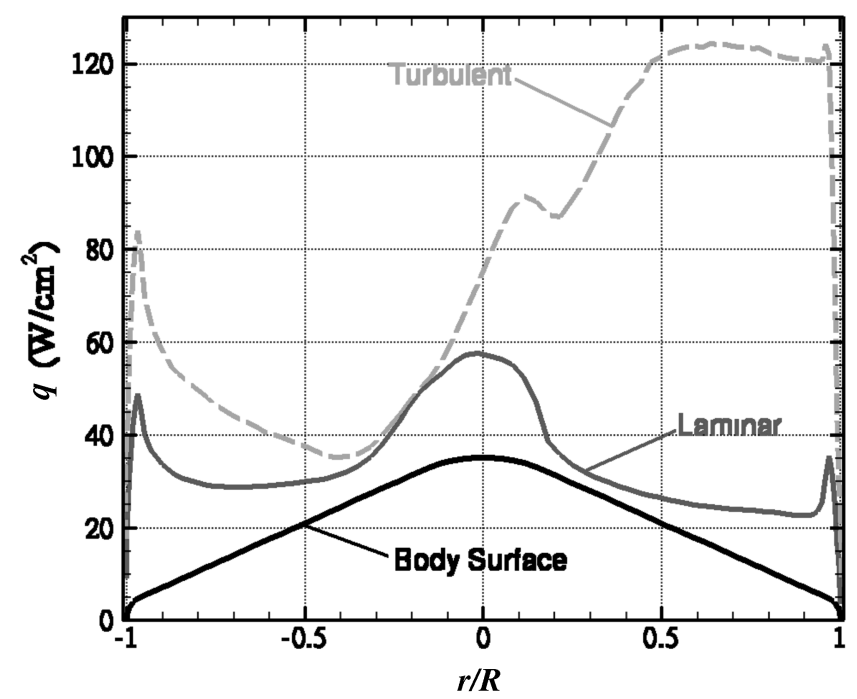

Fig. 1 Representative computed laminar and turbulent centerline heating rates on MSL.

heat loads on the lee side of the forebody, rather than by those at the stagnation point. Unfortunately, there has been little experimental data available to validate the computational predictions for this flow environment, which leads to large uncertainties in flight aeroheating predictions.

A previous MSL configuration (also a $70 \mathrm{deg}$ sphere cone) was tested in the Langley Research Center Mach 6 air tunnel with an emphasis on heating augmentation due to possible forebody heat shield penetrations [3]. The results showed that turbulent heating levels downstream of isolated roughness elements on the lee side of the vehicle were large, and in fact exceeded even the smooth-wall computational predictions [4]. However, these tests were not intended to measure lee side turbulent heat fluxes; transition was forced due to large cavities on the model, and thus it was not known whether such high heating levels would be observed in a naturally developed turbulent boundary layer. In addition, these tests were conducted in low enthalpy air, rather than the high enthalpy $\mathrm{CO}_{2}$ atmosphere that would be encountered during Martian entry.

As a follow-on to the previous experiments, a test series is conducted in the California Institute of Technology T5 shock tunnel facility, and the shots are simulated using the same computational fluid dynamics (CFD) tools and physical models that are currently being employed for the design of the flight vehicle. These tests are conducted on a $5 \%$ scale model of the MSL geometry in pure $\mathrm{CO}_{2}$ at freestream enthalpies representative of those experienced in flight. The primary objectives are to obtain experimental heat transfer data, use the data to validate the computational tools in the laminar heating environment, and determine whether the predicted high lee side heating levels occur for naturally transitioned turbulent flows. Secondary objectives are to determine the ability of the current design turbulence models to predict turbulent heating levels and to gain some insight into the appropriate transition criteria to apply to this type of flowfield. Additional testing has also been conducted in the high enthalpy LENS shock tunnel at the Calspan University of Buffalo Research Center as well as the Langley Mach 6 wind tunnel; the results of these tests are presented in [5].

This test series is intended to be complimentary to a similar round of testing in pure $\mathrm{N}_{2}$ and $\mathrm{N}_{2} / \mathrm{CH}_{4}$ mixtures using the same model, conducted in support of the In-Space Propulsion program Titan aerocapture concept. The results of this complimentary test series are reported in [6].

\section{Experimental Setup}

The experiments were performed in the T5 free-piston shock tunnel at the California Institute of Technology. This facility is described in detail in Hornung et al. [7] Briefly, T5 is a piston-driven reflected shock tunnel that generates hypervelocity flows which

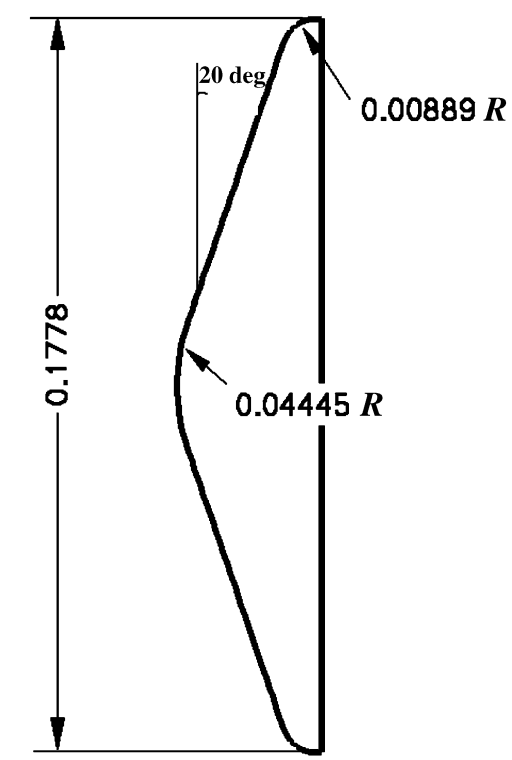

Fig. 2 Schematic of MSL scale model as tested. All dimensions in meters.

simulate real gas flight environments. A piston driven by high pressure air is used to heat and accelerate a driver gas to a high temperature and pressure in a very short time. This driver gas shockheats the test gas that is expanded through a nozzle to a high velocity producing a high enthalpy flow of sufficient duration to ensure steady flow over the test model.

The test model is a 70 deg sphere cone, with dimensions given in Fig. 2. The base diameter is $0.1778 \mathrm{~m}$ (7 in.) or approximately $5 \%$ of the flight scale. The relative dimensions match the current MSL heat shield design except for the shoulder radius, which is specified as $10 \%$ of the base radius rather than $5 \%$ for the current flight baseline due to an MSL design change after the model was constructed. The model is constructed of SS304 hardened tool stainless steel and instrumented with 22 fast response type-E thermocouples on the forebody. The thermocouples are constructed of chromel-constantan alloy. The locations of each thermocouple are given in Table 1 in cylindrical coordinates in terms of $r / R$, the radial distance from the apex normalized by the model radius, and the angle $\phi$, defined as $0 \mathrm{deg}$ on the lee centerline and $180 \mathrm{deg}$ on the wind centerline. Because a primary test objective was to determine lee side turbulent heating levels, the majority of the thermocouples were placed on the centerline and on the lee side of the model. Two thermocouples were mirrored across the pitch plane. Mirrored thermocouples serve two purposes: they permit a determination of inadvertent sideslip angle during the test and, for the turbulent cases, an indication of asymmetric transition. Figure 3 is a photograph of the model with the sting attachment showing the locations of the thermocouple plugs. The plugs are inserted into the holes shown and are flush to the model surface. The thermocouple data (sampled at $200 \mathrm{kHz}$ ) are averaged

Table 1 Thermocouple locations on the model. $R$ is the model radius $(0.0889 \mathrm{~m})$

\begin{tabular}{cccc}
\hline \hline$r / R$ & $\phi(\mathrm{deg})$ & $r / R$ & $\phi(\mathrm{deg})$ \\
\hline 1.0000 & 0 & 1.0000 & 180 \\
0.8422 & 0 & 0.5066 & 30 \\
0.6744 & 0 & 0.5618 & 39.6 \\
0.5066 & 0 & 0.3388 & 45 \\
0.3388 & 0 & 0.6744 & 60 \\
0.1710 & 0 & 0.5066 & 315 \\
0.0000 & Apex & 0.6744 & 210 \\
0.1710 & 180 & 0.5066 & 225 \\
0.3388 & 180 & 0.3388 & 225 \\
0.6744 & 180 & 0.6744 & 240 \\
0.8422 & 180 & 0.6744 & 270 \\
\hline \hline
\end{tabular}




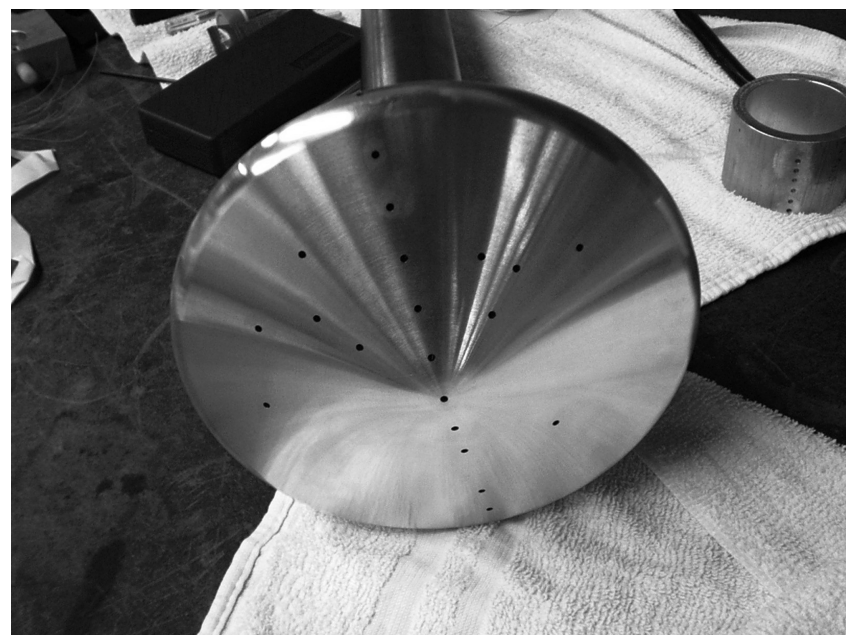

Fig. 3 Photograph of model showing placement of thermocouple ports.

over a time window chosen according to the shot conditions, i.e., accounting for the starting process and onset of driver gas contamination. The actual test time varied from shot to shot, but averaged approximately $1 \mathrm{~ms}$. The error bars shown on the figures are the standard deviation of the signal from this average. Therefore, large error bars can be an indication of the level of unsteadiness of the signal during the averaging time, possibly due to turbulent transition. Additional details of the experimental setup are provided in [6].

\section{Numerical Methodology}

The flowfield computations are performed using the CFD code DPLR [8]. Additional computations are performed with the LAURA code [9] to ensure consistency between the heat transfer rates computed by the two codes. LAURA and DPLR are the primary codes used to determine the predicted flight environments for the MSL mission, and both have been used extensively for planetary entry and ground test simulations. Both are parallel multiblock finitevolume codes that solve the reacting Navier-Stokes equations including finite-rate chemistry and the effects of thermal nonequilibrium. The Euler fluxes in DPLR are computed using a modified (low-dissipation) form of Steger-Warming flux vector splitting, [10] with third-order spatial accuracy obtained via MUSCL extrapolation coupled with a minmod limiter [11]. LAURA uses a second-order Roe scheme [12]. Viscous fluxes in both codes are computed to second-order accuracy using a central difference approach.

All of the shots for this series are conducted in pure $\mathrm{CO}_{2}$. At the freestream enthalpies considered here, the post-shock gas will be partially dissociated but negligibly ionized; therefore, a five-species $\left(\mathrm{CO}_{2}, \mathrm{CO}, \mathrm{O}_{2}, \mathrm{C}, \mathrm{O}\right)$, six-reaction finite-rate chemistry model is used [13]. The flow is assumed to be in thermal nonequilibrium, according to the two-temperature model of Park, [14] in which the vibrational modes of the gas are in equilibrium with each other, but out of equilibrium with the translational-rotational modes. Vibrational relaxation is modeled using a Landau-Teller formulation, where relaxation times are fit to the expression from Millikan and White, [15] assuming that each vibrational mode behaves as a simple harmonic oscillator. Relaxation times for the vibrational modes of $\mathrm{CO}_{2}$ were taken from Camac, [16] and those for $\mathrm{CO}$ and $\mathrm{O}_{2}$ were taken from Park [13]. Because of the fast relaxation time of $\mathrm{CO}_{2}$, the level of thermal nonequilibrium in the flowfield is small, although it is modeled in the current results.

Viscous transport and thermal conductivity are modeled using the binary collision-integral based mixing rules presented by Gupta et al., [17] which have been shown $[18,19]$ to be good approximations of the more accurate Chapman-Enskog relations in this flow regime. The self-consistent effective binary diffusion method [20] is used to compute the species diffusion coefficients. This method allows for the variations in species diffusion coefficients to be accurately modeled without sacrificing the requirement that the diffusion velocities sum identically to zero, and has been shown [21] to accurately model the true multicomponent diffusion velocities.

Turbulent simulations are computed using the Baldwin-Lomax turbulence model [22] as well as the two-equation shear stress transport (SST) model of Menter [23]. Both models include corrections for compressible flow [24]. The Baldwin-Lomax model is frequently used to compute design turbulent heating for Mars entry simulations, [2] but its accuracy in predicting lee side turbulent heating levels on lifting blunt cones is unknown. The SST model was shown to be reasonably accurate for a variety of hypersonic flows in a recent model validation study [24]. For turbulent flows the predicted flight heating is sensitive to the choice of the turbulent Schmidt number $S c_{T}$. Unfortunately, the correct value of $S c_{T}$ for high enthalpy wall-bounded flows is unknown. Values in the range $0.5 \leq$ $S c_{T} \leq 1.0$ are typically used. The impact of the choice of the turbulent Schmidt number for these shock tunnel cases will be explored in the results section. All turbulent solutions are computed assuming that transition begins at the stagnation point. A key result of this paper is to determine the applicability of these standard "design" turbulence models to the computation of heat transfer rates for these flows, which will help to define the uncertainty levels in the flight environment predictions.

Because of the short test duration, the model temperature does not vary significantly during the shot, therefore, an isothermal wall is assumed $\left(T_{w}=300 \mathrm{~K}\right)$ for all cases. Surface catalysis will potentially play a significant role in the net heating, particularly for the higher enthalpy flows. Catalytic properties of materials in $\mathrm{CO}_{2}$ have not been characterized as extensively as in air, although some recent studies [25-28] have explored possible mechanisms on certain materials. However, none of these studies examined materials and conditions relevant to the current test series. Therefore, three catalysis models are explored in this paper. The simplest model is to assume a noncatalytic surface. At the other extreme is the "supercatalytic" wall model, [29] in which the composition at the wall is forced to its lowest chemical enthalpy state (in this case pure $\mathrm{CO}_{2}$ ). This model is not physically based in that finite-rate surface reactions are not modeled, but it serves as a useful limiting case because it is conservative: essentially all of the chemical enthalpy in the boundary layer is recovered at the wall. This is the model currently baselined for MSL design [2]. Finally, the Mitcheltree catalysis model [30] developed during the Mars Pathfinder program is also employed. In the Mitcheltree model, $\mathrm{CO}_{2}$ recombination at the surface is modeled as a two-step reaction involving $\mathrm{CO}$ molecules and $\mathrm{O}$ atoms, with two parallel paths given by

$$
\begin{gathered}
\mathrm{O}+(s) \rightarrow \mathrm{O}_{s} ; \quad \mathrm{CO}+\mathrm{O}_{s} \rightarrow \mathrm{CO}_{2} \\
\mathrm{CO}+(s) \rightarrow \mathrm{CO}_{s} ; \quad \mathrm{O}+\mathrm{CO}_{s} \rightarrow \mathrm{CO}_{2}
\end{gathered}
$$

where $s$ is a surface adsorption site. The process is assumed to be fully catalytic, but the rate of recombination is limited by the diffusion rate of the required reactants $\mathrm{O}$ and $\mathrm{CO}$ to the surface.

Freestream conditions for all cases are determined by computing the nozzle expansion from the known reservoir conditions to the test section with DPLR, including the effects of thermal nonequilibrium and finite-rate chemistry. The gas in the reservoir is assumed to be in thermochemical equilibrium. The reservoir pressure is taken as the average of the readings measured with transducers at two locations. Typically, the pressure transducer readings are within $2 \%$. The reservoir enthalpy is computed from the measured shock speed, reservoir pressure, and initial fill conditions using the equilibrium shock tube calculation code [31]. The nozzle boundary layer was assumed to be entirely laminar due to the rapid expansion. This assumption is not expected to affect the computed freestream conditions, as calculations assuming that the nozzle wall was completely turbulent using the Baldwin-Lomax model predicted nearly identical centerline flow properties. The computations predict that flow properties such as Mach number, pitot pressure, density, and temperature vary by less than $3 \%$ at the nozzle exit across a $20 \mathrm{~cm}$ 
Table 2 Shot matrix and computed freestream conditions for the test series

\begin{tabular}{|c|c|c|c|c|c|c|c|c|c|c|}
\hline Shot \# & $h_{0}(\mathrm{MJ} / \mathrm{kg})$ & $p_{0}(\mathrm{MPa})$ & $\alpha(\operatorname{deg})$ & $u_{\infty}(\mathrm{m} / \mathrm{s})$ & $\rho_{\infty}\left(\mathrm{kg} / \mathrm{m}^{3}\right)$ & $T_{\infty}(\mathrm{K})$ & $c\left[\mathrm{CO}_{2}\right]$ & $c\left[\mathrm{O}_{2}\right]$ & $c[\mathrm{CO}]$ & $c[\mathrm{O}]$ \\
\hline 2254 & 10.6 & 19.45 & 0 & 3367 & 0.03116 & 1828 & 0.55 & 0.151 & 0.287 & 0.012 \\
\hline 2255 & 11.3 & 52.55 & 0 & 3514 & 0.07829 & 2188 & 0.592 & 0.139 & 0.259 & 0.009 \\
\hline 2256 & 6.1 & 23.35 & 0 & 2732 & 0.05700 & 1407 & 0.8307 & 0.061 & 0.108 & 0.0003 \\
\hline 2257 & 11.7 & 44.7 & 11 & 3556 & 0.06463 & 2170 & 0.561 & 0.148 & 0.28 & 0.011 \\
\hline 2258 & 4.9 & 63.9 & 11 & 2547 & 0.18542 & 1317 & 0.924 & 0.027 & 0.049 & 0 \\
\hline 2259 & 5.8 & 77.75 & 11 & 2721 & 0.19100 & 1496 & 0.897 & 0.037 & 0.066 & 0 \\
\hline 2261 & 6.13 & 22.2 & 11 & 2729 & 0.05440 & 1402 & 0.827 & 0.063 & 0.11 & 0 \\
\hline 2262 & 9.7 & 11.9 & 11 & 3204 & 0.02131 & 1627 & 0.569 & 0.146 & 0.275 & 0.01 \\
\hline 2263 & 5.7 & 71 & 16 & 2701 & 0.17769 & 1470 & 0.898 & 0.037 & 0.065 & 0 \\
\hline 2264 & 11.6 & 58.9 & 16 & 3567 & 0.08437 & 2243 & 0.586 & 0.14 & 0.264 & 0.01 \\
\hline 2266 & 6.4 & 25.05 & 16 & 2777 & 0.05931 & 1456 & 0.8186 & 0.066 & 0.115 & 0.0004 \\
\hline 2267 & 9.5 & 20.6 & 16 & 3227 & 0.03639 & 1754 & 0.622 & 0.13 & 0.241 & 0.007 \\
\hline 2268 & 7.1 & 32.3 & 16 & 2900 & 0.07049 & 1597 & 0.7932 & 0.075 & 0.131 & 0.0008 \\
\hline 2269 & 7.1 & 31.5 & 11 & 2900 & 0.06861 & 1591 & 0.788 & 0.0792 & 0.132 & 0.0008 \\
\hline 2270 & 10.4 & 29.95 & 11 & 3363 & 0.04837 & 1935 & 0.5995 & 0.137 & 0.255 & 0.0085 \\
\hline 2271 & 15.3 & 29.55 & 11 & 4004 & 0.03358 & 2286 & 0.354 & 0.193 & 0.411 & 0.042 \\
\hline 2272 & 10.6 & 29.65 & 11 & 3389 & 0.04722 & 1951 & 0.587 & 0.141 & 0.263 & 0.009 \\
\hline 2273 & 14.6 & 29.45 & 11 & 3898 & 0.03519 & 2244 & 0.383 & 0.189 & 0.392 & 0.036 \\
\hline 2274 & 11.2 & 63.95 & 11 & 3508 & 0.09474 & 2223 & 0.615 & 0.132 & 0.245 & 0.008 \\
\hline 2275 & 13.7 & 61.5 & 11 & 3830 & 0.07618 & 2447 & 0.486 & 0.167 & 0.327 & 0.02 \\
\hline
\end{tabular}

core region, therefore, the freestream conditions in the CFD are taken to be uniform.

\section{Results}

A total of 20 usable shots are run in pure $\mathrm{CO}_{2}$ over a range of total enthalpies $h_{0}$ from $4.9-15.3 \mathrm{MJ} / \mathrm{kg}$ and stagnation pressures $p_{0}$ from $12-78 \mathrm{MPa}$. Note that the total enthalpy reported in this paper is computed solely from the kinetic component $\left(h_{o}=\frac{1}{2} u_{\infty}^{2}+p / \rho\right)$, neglecting the large negative formation enthalpy of $\mathrm{CO}_{2}$. Three shots were run at 0 deg angle of attack, while the remainder were run at $\alpha=11$ and $\alpha=16 \mathrm{deg}$. Table 2 shows the final shot matrix, as well as the computed freestream conditions for each case. In Table 2, the freestream conditions are given in terms of the computed velocity, density, temperature, and mass fractions of $\mathrm{CO}_{2}, \mathrm{CO}, \mathrm{O}_{2}$, and $\mathrm{O}$. The freestream mass fraction of $\mathrm{C}$ atoms was negligibly small in all cases. Only a few of the shots are discussed in detail in this paper, but comparisons of computed and experimental heat transfer are given for all 20 shots in Appendix A of [32].

The enthalpy and stagnation pressure range for this test series was chosen to encompass as much of the actual MSL flight envelope as possible, including the laminar, transitional, and fully turbulent flow regimes. Like all ground-based high enthalpy test facilities, much of the freestream enthalpy is contained in the thermal and chemical modes of the gas rather than in kinetic energy. As a result, freestream temperatures are higher and freestream Mach numbers are considerably lower than would be observed in flight. Given that the purpose of the tests is to evaluate turbulent heating, it is desired to match the flight enthalpy and the Reynolds number based on either diameter or momentum thickness as closely as possible. A comparison of the T5 test conditions to representative (circa 2004) MSL design trajectories is shown in Fig. 4. Peak heating in flight occurs at about $h_{0}=12 \mathrm{MJ} / \mathrm{kg}$ and peak pressure occurs at about $h_{0}=7 \mathrm{MJ} / \mathrm{kg}$, as shown in the figure. From Fig. 4, we see that the enthalpy range of the shots in T5 spans much of the flight trajectories. $R e_{D}$ values are somewhat smaller than observed in flight (Fig. 4a). A better nondimensional parameter to match for turbulent heating tests is the momentum thickness Reynolds number, which is often used as a predictor of smooth-wall transition onset [2]. Figure $4 \mathrm{~b}$ shows the comparison of peak $R e_{\theta}$ vs $h_{0}$ for the T5 shots. While peak $R e_{\theta}$ values in T5 are somewhat lower than the maximum encountered in flight, good agreement is obtained before and near the peak heating point on the trajectory, where transition onset is predicted to occur.

\section{A. Axisymmetric Cases}

Before comparison with the experimental data, it is desired to first examine the impact of the various wall catalysis models on the predicted heat transfer rate. Figure 5 shows the computed laminar heat transfer along the model centerline for shot 2254 for three different catalysis models: a noncatalytic surface, a Mitcheltree [30] surface catalysis, and a supercatalytic surface. Shot 2254 is a zero angle of attack case at high enthalpy and low pressure $\left(h_{0}=10.6 \mathrm{MJ} / \mathrm{kg}, \quad p_{0}=19.4 \mathrm{MPa}\right)$, and as such provides a straightforward (low $R e$, likely laminar) starting point for the CFD analysis. As can be seen in the figure, the heat transfer is highest at the stagnation point (the apex at $y=0$ ), reaching a value of about $1100 \mathrm{~W} / \mathrm{cm}^{2}$ for the supercatalytic solution. Smaller peaks near the maximum diameter point are due to flow expansion around the shoulders of the model.

The choice of wall catalysis model has a large impact on the computed surface heating, as seen in Fig. 5. Interestingly, while the

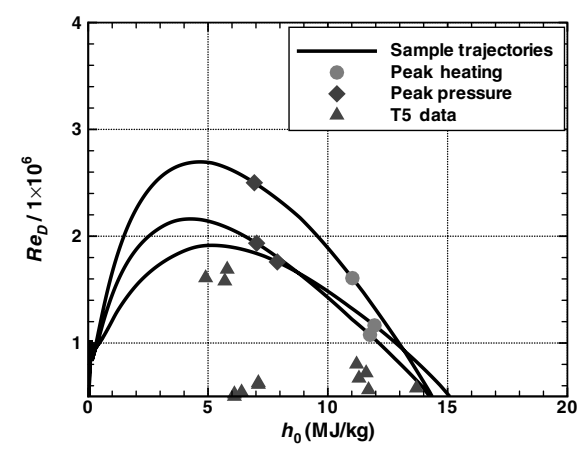

a) b)

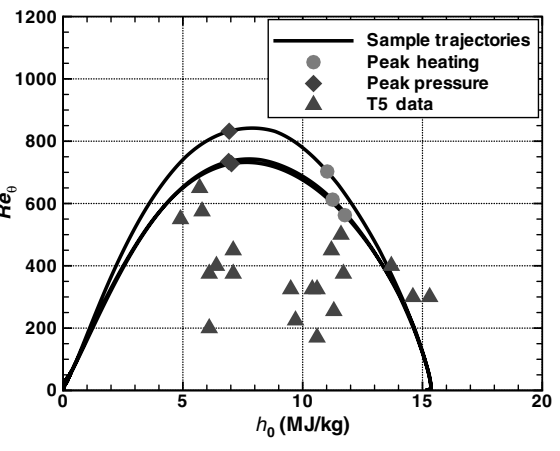


supercatalytic model predicts a stagnation point heat transfer rate $70 \%$ higher than the noncatalytic model for this case, the Mitcheltree [30] model is only about $10 \%$ higher than the noncatalytic. This result is different from what is observed in flight calculations of Mars entry, [30] where the Mitcheltree model predicts a heat transfer rate significantly higher than noncatalytic. The results for the present T5 cases are different from flight due to the details of the chemical kinetics. The freestream for shot 2254 consists primarily of $\mathrm{CO}_{2}, \mathrm{CO}$, and $\mathrm{O}_{2}$ (see Table 2 ) because most of the oxygen atoms produced by $\mathrm{CO}_{2}$ dissociation in the reservoir are recombined into $\mathrm{O}_{2}$ before and during the nozzle expansion. Figure 6 a shows the computed species mole fractions along the stagnation streamline for this case, assuming Mitcheltree surface kinetics. From the figure, we see that the shock produced around the model is not strong enough to dissociate all of the remaining molecules, therefore, there is as much $\mathrm{O}_{2}$ as there is monatomic oxygen behind the shock wave. Figure $6 \mathrm{~b}$ shows a closeup of the boundary layer region. Computed mole fractions are shown for the noncatalytic, Mitcheltree, and supercatalytic wall models. There is little difference in the amount of $\mathrm{CO}_{2}$ generated at the wall between the noncatalytic and Mitcheltree models for two reasons. First, the Mitcheltree catalysis model is limited by the diffusion of $\mathrm{O}$ atoms to the surface, and much of the oxygen is trapped as $\mathrm{O}_{2}$ at these conditions. Second, due to the high density, most of the free $\mathrm{O}$ atoms are actually undergoing gas-phase recombination with each other or with the $\mathrm{CO}$ molecules in the boundary layer before the wall surface. In contrast, at flight conditions, $\mathrm{CO}_{2}$ is almost completely dissociated in the shock layer leading to large concentrations of $\mathrm{O}$ atoms at the boundary layer edge, and lower pressures lead to less gas-phase recombination in the boundary layer. The computed mole fractions for the supercatalytic wall model shown in Fig. 6b indicate much higher wall concentrations of $\mathrm{CO}_{2}$ because the imposed boundary

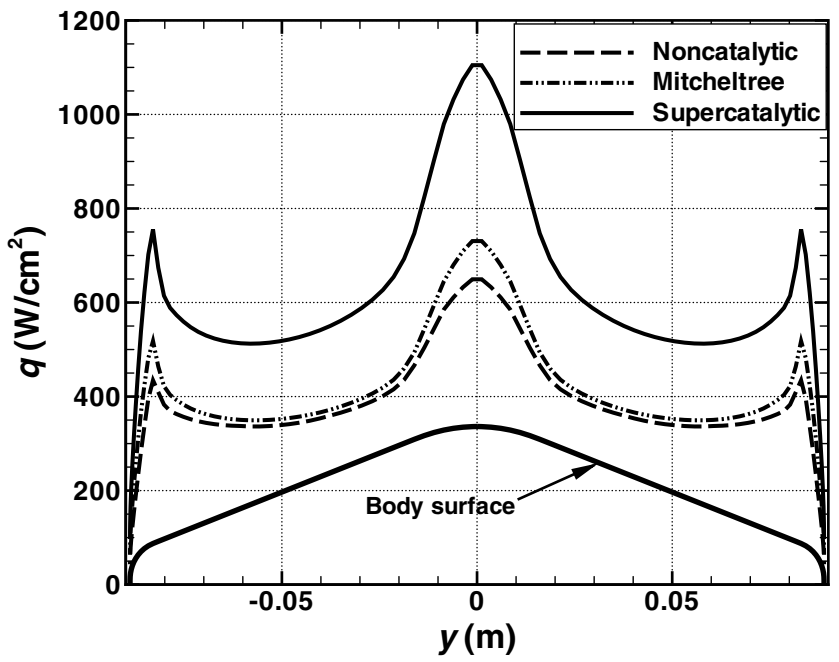

Fig. 5 Predicted catalytic effect on laminar centerline heating for shot 2254.

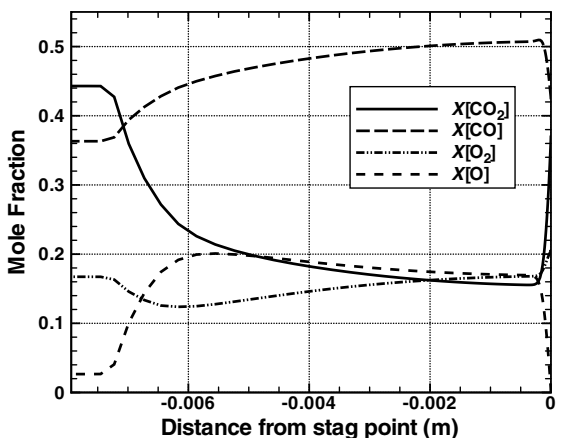

a) condition is forcing the $\mathrm{CO}$ and $\mathrm{O}_{2}$ to recombine. The net result of this forced supercatalytic wall recombination is much higher predicted heating rates, as shown in Fig. 5. At lower enthalpies, there is even less difference between the noncatalytic and Mitcheltree wall models, as shown in Fig. 7 for shot $2256\left(h_{0}=6.1 \mathrm{MJ} / \mathrm{kg}\right.$, $p_{0}=23.4 \mathrm{MPa}, \alpha=0 \mathrm{deg}$ ). One other potential wall reaction is the homogeneous recombination of $\mathrm{O}$ atoms to form $\mathrm{O}_{2}$. Although results are not shown for this mechanism in Fig. 5, it is clear that the net heat transfer for this model would be even lower than that for the Mitcheltree model, since the wall reactions are limited by $\mathrm{O}$ atom diffusion, and the $\mathrm{O}+\mathrm{CO}$ surface reaction modeled in the Mitcheltree mechanism will release more than twice as much energy for a given $\mathrm{O}$ atom number density than the $\mathrm{O}+\mathrm{O}$ reaction. Figure 8 shows the comparison between the CFD simulations and the test data for shot 2256. The error bars on the test data are computed in the manner discussed in Sec. II, including the effects of temporal fluctuations during the usable test time. From the figure, we see that the laminar DPLR result is within $10 \%$ of the test data when the supercatalytic wall boundary condition is employed, whereas the noncatalytic simulation underpredicts the measured heat transfer rates by nearly $50 \%$ at the apex and about $35 \%$ on the cone flank. The same results hold for the other $\alpha=0 \mathrm{deg}$ cases as well. Similar trends are also observed in the tests performed in the LENS shock tunnel [5]. It is somewhat surprising that the supercatalytic model accurately predicts the heat transfer for these cases because, as stated in the preceding section, this model was developed mainly as a convenient means to determine an upper bound on the predicted heat flux. Given that, as discussed, the post-shock gas primarily consists of $\mathrm{CO}$ and a mix of molecular $\mathrm{O}_{2}$ and $\mathrm{O}$ atoms, the only way that the wall can behave as a supercatalytic surface is if there is an efficient surface mechanism to convert $\mathrm{CO}$ and $\mathrm{O}_{2}$ into $\mathrm{CO}_{2}$. Such a mechanism does exist and is well known in the catalytic converter

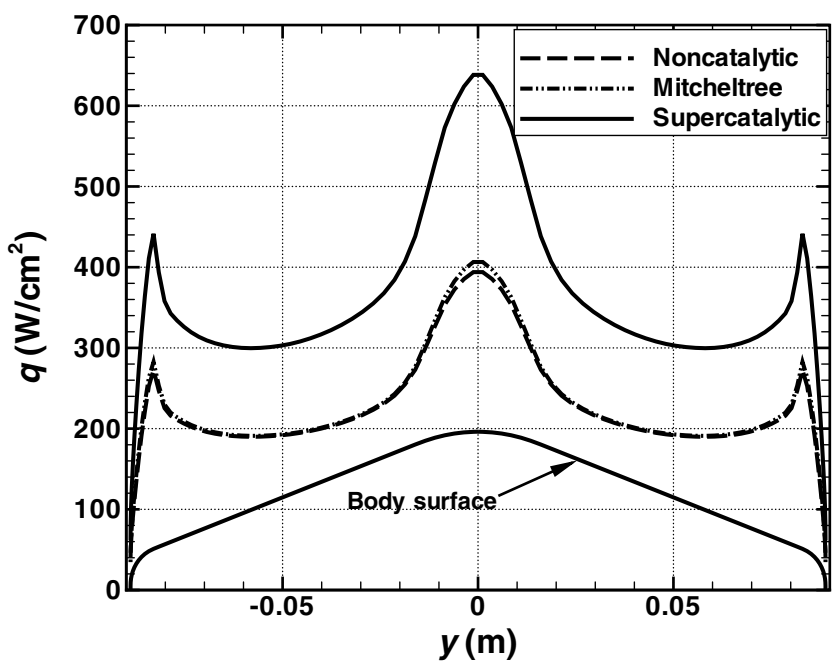

Fig. 7 Predicted laminar centerline heating for shot 2256.

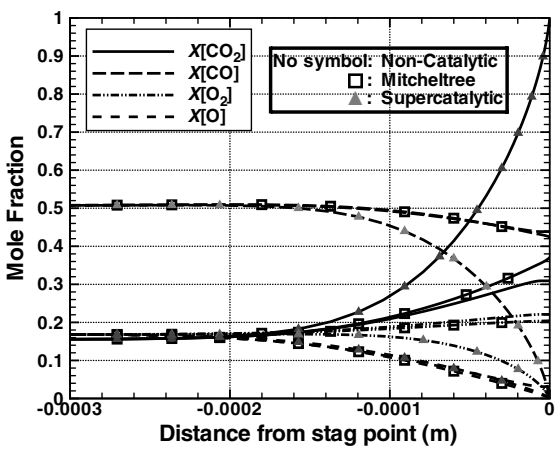

b)

Fig. 6 a) Computed mole fractions along the stagnation streamline for shot 2254; b) Expanded view of the boundary layer. 


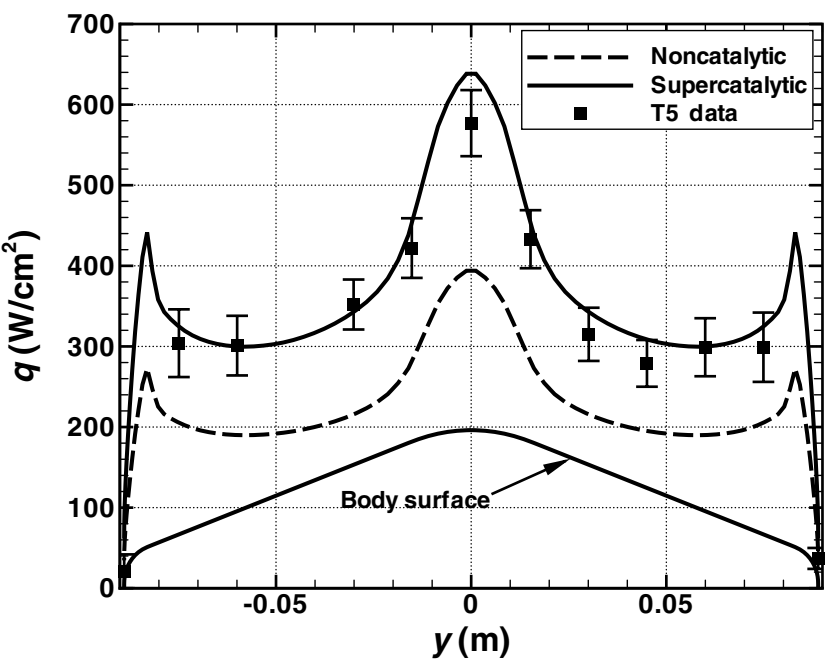

Fig. 8 Comparison of laminar computation to data for shot 2256.

community [33-35]. The rate of $\mathrm{CO}_{2}$ production has been measured on platinum surfaces, where it is observed to be strongly temperature dependent, with a maximum around $180^{\circ} \mathrm{C}$ [33]. To our knowledge, the efficiency or even existence of such a mechanism on stainless steel or chromel-constantan (thermocouple material) surfaces has never been measured. Previous measurements on quartz [26] failed to detect any signs of $\mathrm{CO}+\mathrm{O}$ or $\mathrm{CO}+\mathrm{O}_{2}$ recombination in weakly dissociated $\mathrm{O}_{2} / \mathrm{O} / \mathrm{CO}$ mixtures, although $\mathrm{O}+\mathrm{O}$ recombination was detected. However, pending additional analysis, it seems possible that such a surface reaction may be occurring on the metallic surface of the model during the tests.

None of the three axisymmetric cases (shots 2254-2256) showed any clear experimental evidence of transition to turbulence on the cone flank [32].

\section{B. Three-Dimensional Cases}

Figure 9a shows the centerline heating for shot 2257 $\left(h_{0}=11.7 \mathrm{MJ} / \mathrm{kg}, p_{0}=44.7 \mathrm{MPa}, \alpha=11 \mathrm{deg}\right)$. The computed laminar profile looks very similar to the axisymmetric case, with the peak heating occurring at the cone apex rather than the flow stagnation point. The windward side of the cone is somewhat hotter than the leeward side, a result typical of blunt cones at angle of attack. Once again we see that the laminar supercatalytic DPLR computation is generally within $10 \%$ of the experimental data, whereas the noncatalytic computation underpredicts the measured heat transfer by about $40 \%$ at the apex and $35 \%$ on the cone flank. This result holds qualitatively true for all of the laminar shots in this series. The supercatalytic prediction at the cone apex is about $15 \%$ low. This was not generally true for other shots, and could possibly be due to incipient transition near the cone apex.

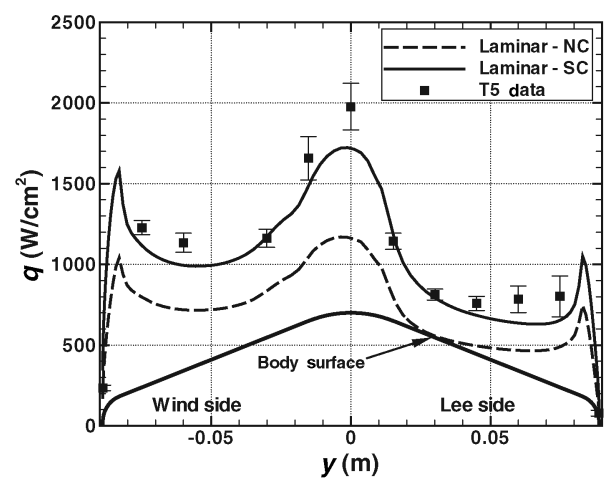

a)

Fig. 9 Comparison of computation to data for shot 2257: a) centerline heating, and b) percent difference at thermocouple locations
Figure $9 \mathrm{~b}$ shows the comparison between the T5 data and the supercatalytic laminar CFD simulation at all 22 thermocouple locations on the model. The data are presented in terms of

$$
q_{\mathrm{diff}}=100 \times\left(q_{\mathrm{CFD}}-q_{\mathrm{T} 5}\right) / q_{\mathrm{T} 5}
$$

at each thermocouple location. The model is viewed face on. Only those thermocouples for which the magnitude of the difference between the CFD and T5 data is greater than 20\% are labeled in Fig. 9b. Given that agreement between the laminar experimental and computed laminar heating rate is generally good, one qualitative indicator of experimental transition on the lee side of the model is a significant underprediction of the experimental heating rates with the laminar CFD simulation. From Fig. 9b, we see that agreement between the computation and the experiment is generally within $20 \%$, although a few points on the leeward side of the cone indicate slightly larger disagreement, perhaps due to incipient transition to turbulence. Note that agreement is poor at the two thermocouples on the wind and lee shoulders. This discrepancy is primarily due to the large lateral heat transfer gradients on the shoulder (see Fig. 9a), which make an accurate measurement of heat transfer extremely

Figure 10 shows the results for shot $2258\left(h_{0}=4.9 \mathrm{MJ} / \mathrm{kg}\right.$, $p_{0}=63.9 \mathrm{MPa}$, and $\alpha=11 \mathrm{deg}$ ). Computations were performed with DPLR and LAURA, assuming both a supercatalytic laminar and a fully turbulent flowfield computed using the Baldwin-Lomax turbulence model with a turbulent Schmidt number of 0.7. Both codes predict nearly identical laminar heating rates, as is typically the case when the same physical models are employed. Small differences at the shoulder are due to different shoulder radii in the two computational grids; the LAURA solutions were run with a scaled

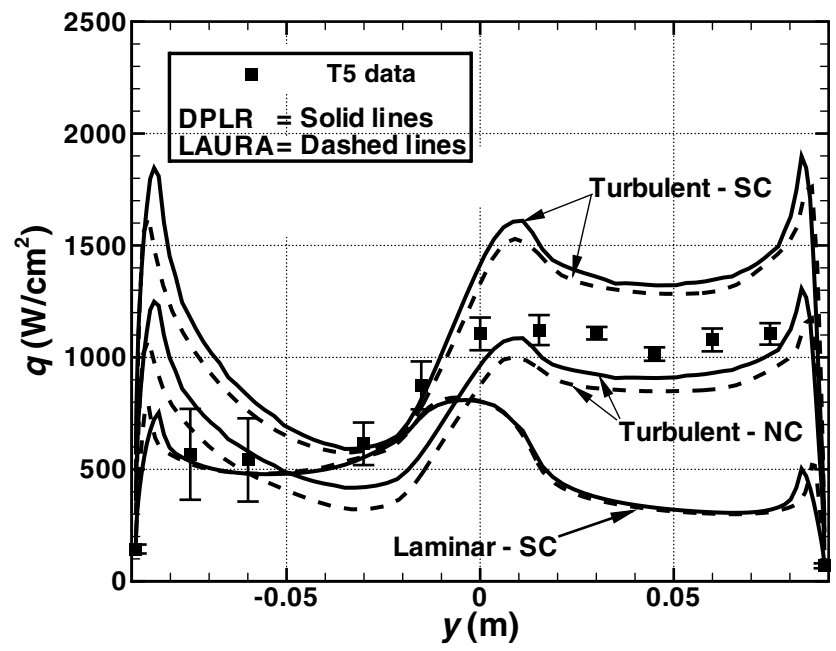

Fig. 10 Comparison of DPLR and LAURA computations for shot 2258.

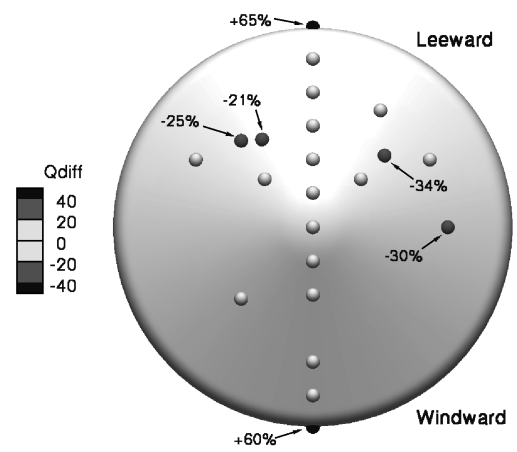

b) difficult with a relatively large thermocouple plug. 
model of the current MSL aeroshell, which has a smaller shoulder radius than the model used for the T5 test series, as discussed in Sec. II. From the calculations, we see that the radius of the shoulder has little impact on the flowfield on the forebody of the sphere cone away from the shoulder expansion region. Also shown is the comparison between the codes for turbulent flows using the Baldwin-Lomax model together with a noncatalytic (NC) and supercatalytic (SC) wall assumption. Although small differences between the codes are seen in Fig. 10 (primarily due to differences in

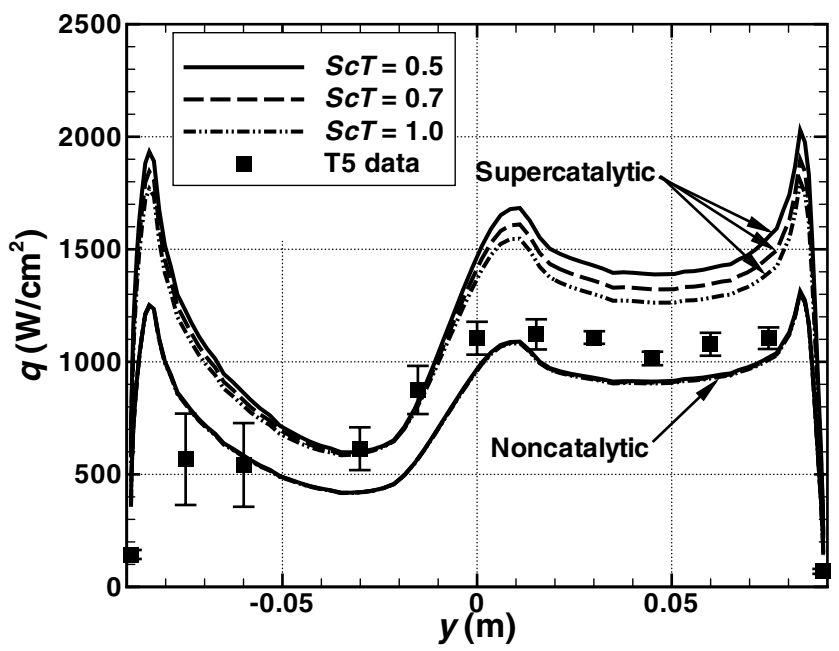

Fig. 11 Sensitivity of computed heating to $S c_{T}$ for shot 2258 .

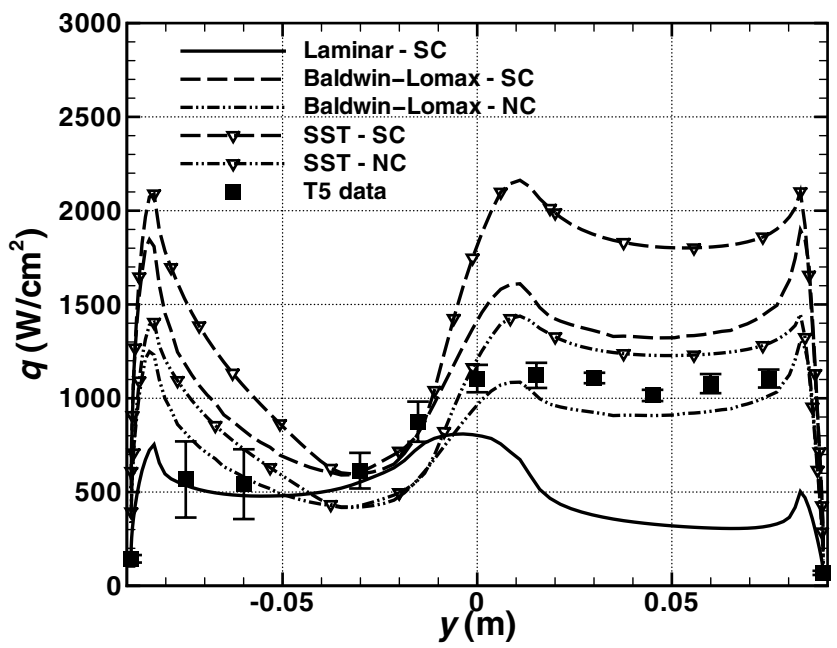

Fig. 12 Comparison of computation to data for shot 2258 using two turbulence models. the implementation of the compressibility corrections to the Baldwin-Lomax model), agreement is within $10 \%$. The same level of agreement was observed for all other cases examined with both codes.

The T5 data for this shot clearly indicate that the flowfield is turbulent on the entire lee side of the vehicle [32]. The wind side appears to have remained laminar, although the large error bars on the wind side centerline data indicate unsteadiness that is possibly the result of transition onset. Interestingly, as shown in Fig. 10, the experimental turbulent heating level on the lee side of the cone is consistent with the noncatalytic Baldwin-Lomax solution, rather than the supercatalytic solution. This is in contrast to the laminar shots, where the noncatalytic solution is always significantly lower than the T5 data. The same result is observed for the other turbulent shots in this series, and also in the simulations of test data from the LENS facility [5]. The reasons for this discrepancy are not clear at this time. If the laminar results are correct and the surface is indeed nearly supercatalytic, it is difficult to understand why the turbulent cases would not also be supercatalytic. The lee side of shot 2258 certainly seems to be a fully developed turbulent flow, with a flat heating level, and small error bars on the experimental data.

One possible reason for this discrepancy is the choice of turbulent Schmidt number. Figure 11 shows the impact of varying $S c_{T}$ on shot 2258 over the commonly used range $\left(0.5 \leq S c_{T} \leq 1.0\right)$. Because the turbulent Schmidt number primarily affects the amount of catalytic heating at the surface, the noncatalytic results should not be sensitive to the value employed. This insensitivity is indeed seen in Fig. 11; the results for all three values of $S c_{T}$ are collapsed into a single line. In contrast, the heating predictions for the supercatalytic wall are somewhat sensitive to the choice of turbulent Schmidt number, varying by about $\pm 5 \%$ over the range of tested values. However, the results in Fig. 11 indicate that the choice of $S c_{T}$ alone cannot account for the disagreement between the supercatalytic solutions and the experimental data. Therefore, the remainder of the turbulent solutions presented in this paper are run with a nominal value of 0.7 for $S c_{T}$.

Given that the Baldwin-Lomax model has not previously been validated for this type of high enthalpy turbulent flow, it is certainly possible that the model is simply inaccurate for these flows. To test this theory, a series of computations were performed using the Menter SST two-equation model with compressibility corrections. Figure 12 compares the computed heat transfer for shot 2258 using the Baldwin-Lomax and Menter SST turbulence models. The Menter SST model predicts about 35\% higher heating than BaldwinLomax on the lee side for both the noncatalytic and supercatalytic wall. The experimental heat transfer on the leeward side roughly splits the difference between the computed heat transfer obtained for the Baldwin-Lomax and the SST turbulence models with a noncatalytic wall, with the SST model being about $15 \%$ above the experimental levels. This overprediction is at the high end but consistent with behavior of the SST turbulence model for other hypersonic flows [24]. The SST calculations for the other turbulent cases show similar agreement to the experimental levels data.

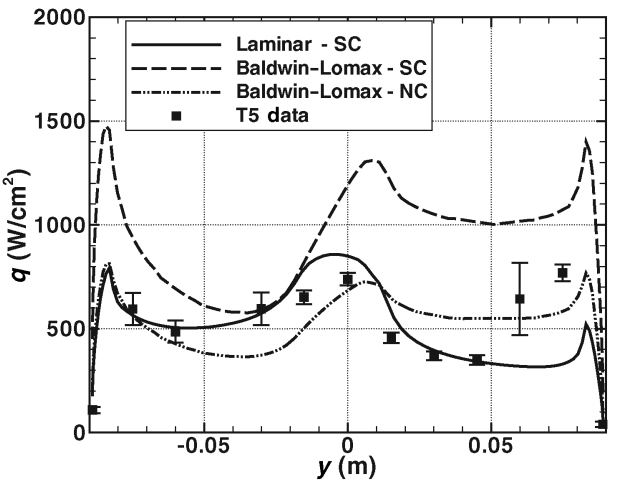

a)

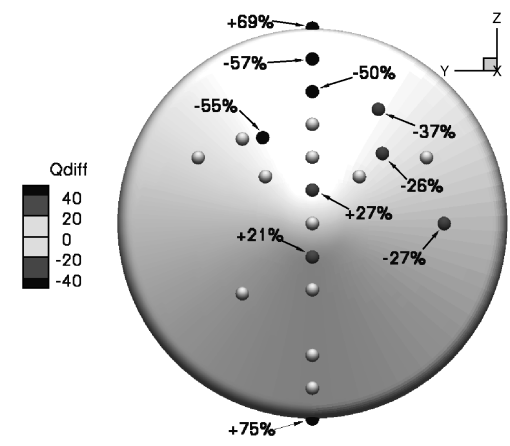

b)

Fig. 13 Comparison of computation to data for shot 2269: a) centerline, and b) percent difference at thermocouple locations. 
Figure 13 shows the results for shot $2269\left(h_{0}=7.1 \mathrm{MJ} / \mathrm{kg}\right.$, $p_{0}=31.5 \mathrm{MPa}$, and $\alpha=11 \mathrm{deg}$ ). This shot seems to be transitional, with the entire wind side and apex region remaining laminar and transition occurring on the lee side near $y=0.06 \mathrm{~m}$. The off-axis thermocouples on the lee side (Fig. 13b) are suggestive of incipient axial transition (sporadic regions where the experimental heat transfer is significantly higher than the computed laminar value), with the effects strongest on the leeward centerline. It is not clear that fully developed turbulent flow is achieved for this case, although the small error bars on the centerline thermocouple at $y=0.075 \mathrm{~m}$ certainly suggest that a steady-state condition has been achieved. As with the other transitional shots in this series, the flow appears to transition from a laminar to a fully turbulent state over a short running length.

\section{Role of Wall Catalysis}

It remains puzzling that the supercatalytic boundary condition seems to give the best agreement with laminar cases, whereas a noncatalytic boundary condition gives the best results for the turbulent cases. Although one explanation is certainly that the turbulence models employed are inaccurate for this type of flow, another possible explanation is that the onset of turbulence has a dampening effect on the catalytic mechanism for these experiments. There are three primary steps to gas-surface catalytic reactions: adsorption, surface reaction, and desorption [36]. For a detailed chemical kinetics description, surface adsorption sites as well as intermediate adsorbed species (e.g., $\mathrm{O}+(s) \rightarrow \mathrm{O}_{s}$ ) will form. For steady conditions, the overall rate of the catalytic reaction will then be governed by a rate-limiting step with each of the remaining steps coming into equilibrium consistent with the overall rate. However, for unsteady conditions, a finite-rate reaction for each step will lead to characteristic time scales associated with unsteady catalytic reaction. For example, as the overall catalytic reaction rate increases, we might expect that the population of occupied surface sites also increases and, for an unsteady flow, this change will take a finite time.

As long as the catalytic time scale is short relative to any unsteadiness, the assumption of equilibrium should prove valid. However, turbulent boundary layers have a characteristic eddy or turbulent burst time scale of $\mathcal{O}\left(3 \delta / u_{e}\right)$ [37], which for the current experimental cases will be of order $5 \mu$ s. Should the catalytic time scale be comparable to, or longer than, the turbulent time scale, the catalytic effect may be damped relative to a time-averaged equilibrium level as experienced by a comparable laminar flow. For the supercatalytic behavior observed in the current laminar cases, however, we do not have experimental knowledge of the specific mechanism, let alone the finite rates associated with each step and a more in-depth study of this phenomenon is required.

\section{Effect of Angle of Attack}

Whereas most of the shots were conducted at the planned flight angle of attack for MSL ( $\alpha=11 \mathrm{deg}$ ), a limited number of shots were also conducted at $\alpha=16 \mathrm{deg}$ to examine the impact of $\alpha$ on laminar and turbulent heating levels. Shots $2268\left(h_{0}=7.1 \mathrm{MJ} / \mathrm{kg}\right.$, $p_{0}=32.3 \mathrm{MPa}$, and $\left.\alpha=16 \mathrm{deg}\right)$ and $2269\left(h_{0}=7.1 \mathrm{MJ} / \mathrm{kg}\right.$, $p_{0}=31.5 \mathrm{MPa}$, and $\alpha=11 \mathrm{deg}$ ) are nearly identical except for the angle of attack. From Fig. 14 we see that the both the experimental computed laminar and turbulent heat transfer for these shots show little sensitivity to angle of attack. In fact, both flows appear to transition at about $y=0.05 \mathrm{~m}$ and reach nearly identical heating levels on the lee side. Although shot 2268 appears to start transition slightly earlier, this could easily be due to shot-to-shot variability. Another comparison can be made between two fully turbulent cases: shots $2263\left(h_{0}=5.7 \mathrm{MJ} / \mathrm{kg}, p_{0}=71.0 \mathrm{MPa}\right.$, and $\left.\alpha=16 \mathrm{deg}\right)$ and $2259\left(h_{0}=5.8 \mathrm{MJ} / \mathrm{kg}, p_{0}=77.8 \mathrm{MPa}\right.$, and $\left.\alpha=11 \mathrm{deg}\right)$, shown in Fig. 15. Once again, there is little effect of angle of attack on either the experimental or computed heat transfer rates. For these shots the experimental heat transfer rate is the same to within experimental uncertainty at every centerline thermocouple location. These results indicate that small angle of attack variations have little impact on

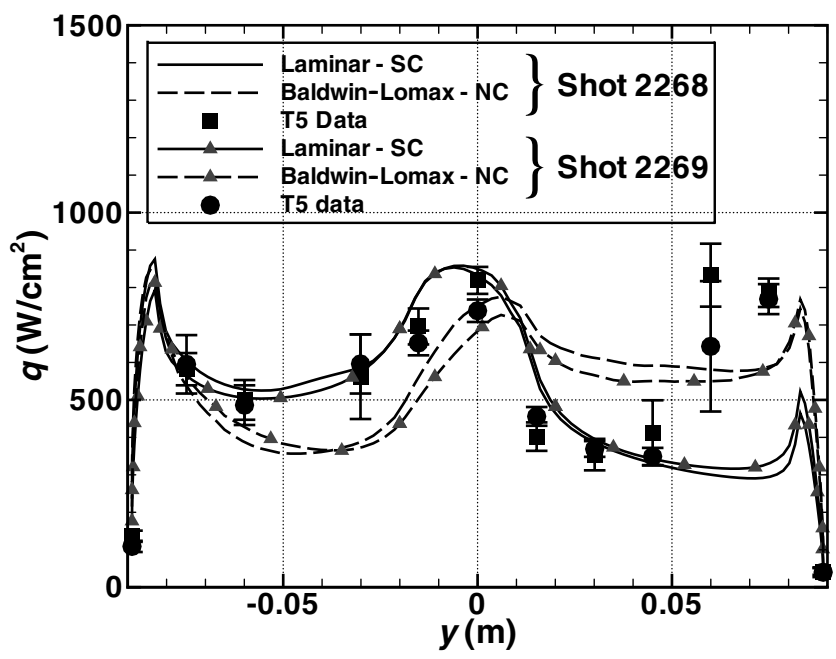

Fig. 14 Impact of $\alpha$ on computed heating for shots 2268 and 2269.

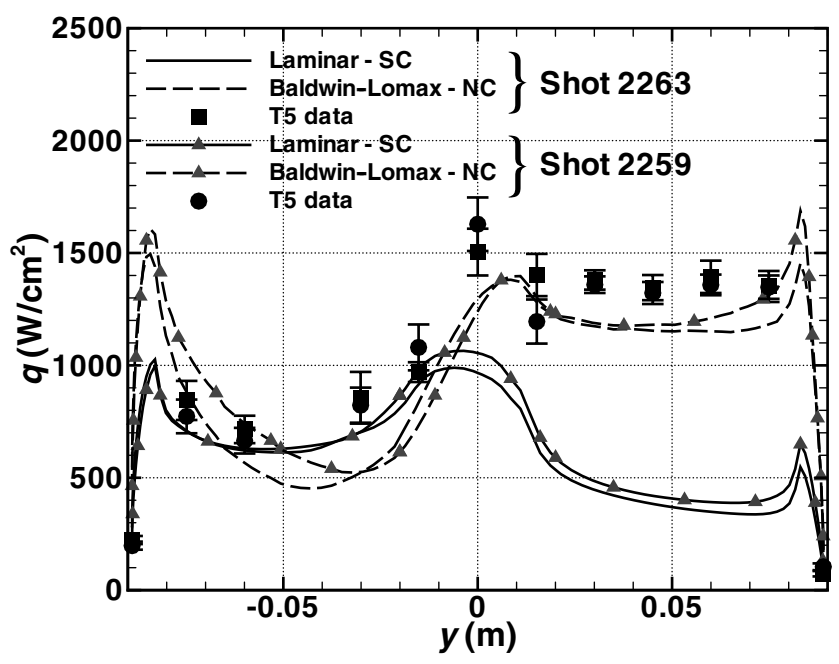

Fig. 15 Impact of $\alpha$ on computed heating for shots 2263 and 2259.

either turbulent heating levels or transition. Clearly, the flow in this range of $\alpha$ is governed by axial transition; crossflow effects have not yet begun to significantly influence the transition mechanism.

\section{E. Effect of Freestream Enthalpy}

Another important result from this test series is a determination of the impact of freestream enthalpy levels on the lee side turbulent augmentation factor (ratio of fully turbulent to laminar heat flux). To assess this effect, we compare two turbulent cases, shots 2274 $\left(h_{0}=11.2 \mathrm{MJ} / \mathrm{kg}, p_{0}=64.0 \mathrm{MPa}\right.$, and $\left.\alpha=11 \mathrm{deg}\right)$ and 2258 $\left(h_{0}=4.9 \mathrm{MJ} / \mathrm{kg}, p_{0}=63.9 \mathrm{MPa}\right.$, and $\left.\alpha=11 \mathrm{deg}\right)$. Figure 16 plots the computed turbulent augmentation factor along the model centerline for both cases. Results are shown for both noncatalytic and supercatalytic walls using the Baldwin-Lomax turbulence model. We see that the computed turbulent augmentation is actually higher for the lower enthalpy shot (2258), reaching a value of about 4.5 times the laminar heating rate near the lee side shoulder. Computed augmentation factors for the high enthalpy shot (2274) reach a maximum of about 3.4 , again near the lee side shoulder. In both cases, the supercatalytic solution has a higher turbulence augmentation than the noncatalytic, but the difference is much larger at higher freestream enthalpy, since the flow is more dissociated and a higher percentage of the total heating is predicted to be due to catalytic effects.

Also shown in Fig. 16 is an estimate of the experimental turbulent augmentation factor for these shots, obtained by taking the ratio of the experimental heating to the computed supercatalytic laminar 


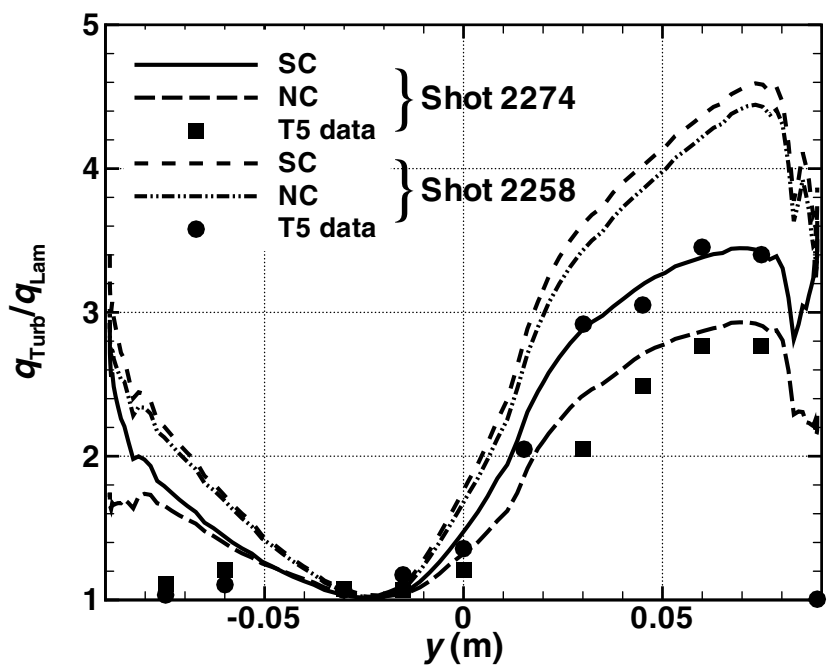

Fig. 16 Impact of freestream enthalpy on turbulent augmentation factors for shots 2274 and 2258.

heating rate. Clearly, the lower enthalpy shot (2274) has a higher augmentation factor (3.5 vs 2.8), analogous to the computational result. However, the experimental augmentation factors are lower than those computed, particularly for the lower enthalpy shot 2258. This result is further evidence that the turbulence model may be inadequate for this type of flow.

\section{F. Wind Side Heating Augmentation}

The fully turbulent simulations all predict nearly the same heating rate at the stagnation point as the laminar cases. However, these models also predict very high heating rates near the wind side shoulder of the blunt cone, in contrast to the observed heating rates in this region. By examination of the centerline data for all shots, [32] it is apparent that in most cases the entire wind side of the model remained laminar, even when the lee side exhibited a fully developed turbulent flow. However, Fig. 17 shows that T5 data from shot 2264 $\left(h_{0}=11.6 \mathrm{MJ} / \mathrm{kg}, p_{0}=58.9 \mathrm{MPa}, \alpha=16 \mathrm{deg}\right)$ seems to indicate somewhat higher heating levels on the wind centerline (near $y=-0.05 \mathrm{~m}$ ) than the laminar predictions. This result is interesting when compared with the apparent wind side heating augmentation reported for similar tests by Olejniczak et al. [6] and Hollis et al., [5] but there is insufficient evidence to reach any conclusions based on these data.

\section{G. Transition Correlation}

The flight vehicle is currently being designed assuming that transition to turbulence occurs when the local $R e_{\theta} / M_{e}$ exceeds some critical value on the order of 200 [2]. Given that the current test series in T5 includes shots that span the laminar, transitional, and fully turbulent flow regimes on the lee side, it makes sense to examine the utility of this criterion based on ground test data. Figure 18 shows computed $R e_{\theta}$ and $R e_{\theta} / M_{e}$ for shot $2258\left(h_{0}=4.9 \mathrm{MJ} / \mathrm{kg}\right.$, $p_{0}=63.9 \mathrm{MPa}$, and $\alpha=11 \mathrm{deg}$ ), a case for which the entire lee side of the model is in turbulent flow. For these T5 cases, the boundary layer edge Mach number is subsonic on the entire forebody of the model, therefore, $R e_{\theta} / M_{e}$ is always significantly larger than $R e_{\theta}$. The peak in the plot of $R_{e} / M_{e}$ near $y=-0.02 \mathrm{~m}$ in Fig. 18 is a spurious result due to the small edge Mach number near the flow stagnation point and can be ignored. From Fig. 18 we see that $R e_{\theta}$ reaches a maximum of about 550 on the lee side for this case, whereas $R e_{\theta} / M_{e}$ reaches a maximum of about 950 . The other shots have a qualitatively similar profile of both $R e_{\theta}$ and $R e_{\theta} / M_{e}$, with a magnitude dependent primarily on the stagnation pressure.

Figure 19 shows the computed transition value of $R e_{\theta} / M_{e}$ for all nonlaminar three-dimensional shots in the test series vs freestream Reynolds number and stagnation enthalpy. The transition value was

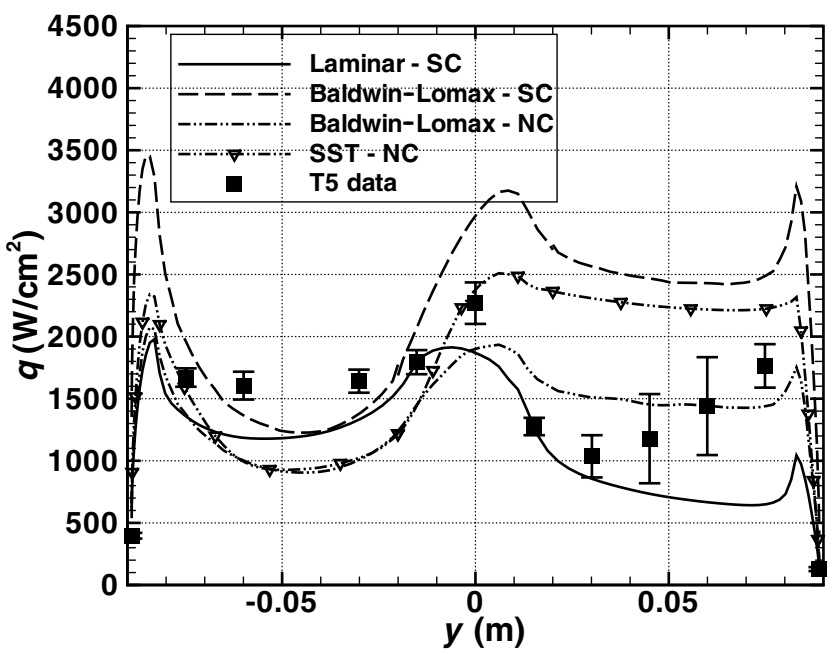

Fig. 17 Comparison of computation to data for shot 2264 showing wind side heating augmentation.

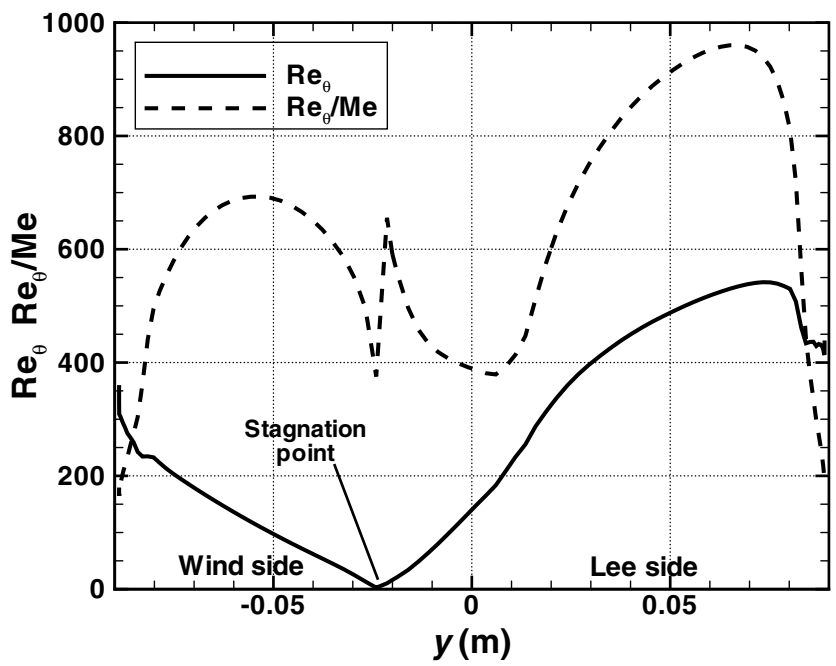

Fig. 18 Computed $R e_{\theta}$ and $R e_{\theta} / M_{e}$ along the model centerline for shot 2258.

determined by examination of the centerline experimental heat transfer data for each case. Transition was assumed to occur at the point where the experimental heat transfer rises significantly above the laminar level. For all of the cases, transition begins on the leeward centerline near the maximum diameter point and travels up the cone to the apex as the Reynolds number increases. Although there is significant scatter in the data, Fig. 19a shows that there is a clear trend that lower $R e_{\theta} / M_{e}$ values are required to promote transition as the freestream Reynolds number is increased. The approximate trend line is shown on Fig. 19a, indicating a critical transition $R e_{\theta} / M_{e}$ ranging from about 550 at $R e_{D}=5 \times 10^{5}$ to about 400 at $R e_{D}=1.55 \times 10^{6}$. Note that transition appeared to occur early in shot 2270, as noted in Fig. 19a. All of these values are higher than is currently used in flight, but the tunnel measurements are of smoothwall transition, while in flight transition will likely be affected by distributed roughness due to ablation of the thermal protection material on the heat shield [38]. In addition, transition in the T5 shock tunnel may be promoted by acoustic disturbances in the nozzle wall boundary layer. The significant differences between the ground test and flight environment make translating these data to a flight prediction of transition difficult, however, the results are useful for predicting transition on similar geometries in T5 or other shock tunnel facilities. Figure $19 \mathrm{~b}$ plots the same data vs total enthalpy. No clear trends are visible, indicating that the transition value of $R e_{\theta} / M_{e}$ is not a strong function of the enthalpy in the flow. 


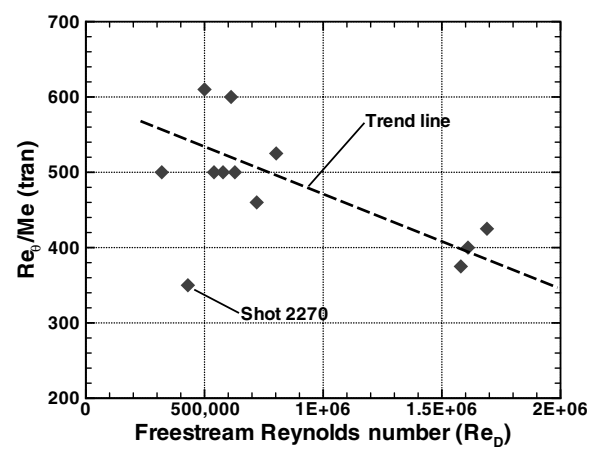

a)

Fig. 19 Computed $R e_{\theta} / M_{e}$ at the transition location as a function of a) $R e_{D}$, and b) $h_{0}$.

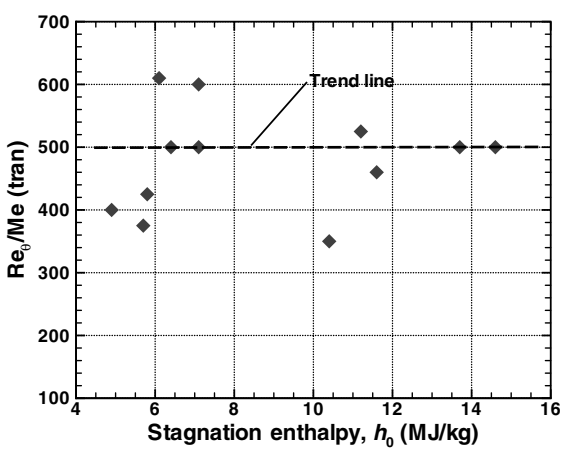

b)

\section{Conclusions}

A series of shots were run in the T5 shock tunnel at the California Institute of Technology to measure laminar and turbulent heating levels on a 70 deg blunt cone at angle of attack in an environment representative of the Mars Science Laboratory entry. A total of 20 shots were obtained over a range of enthalpies and pressures that include data which span the predicted laminar, transitional, and turbulent flight regimes. The range of freestream enthalpies and Reynolds numbers explored during this test series are a reasonably good match to current estimates of the MSL flight trajectory. The T5 data clearly indicate that the lee side turbulent heating augmentation predicted in flight CFD calculations is real and must be accounted for during the design of the thermal protection system for MSL. The amount of lee side heating augmentation due to turbulence appears to be inversely related to the freestream enthalpy. Angle of attack changes from 11 to $16 \mathrm{deg}$ were shown to have minimal impact on both measured and computed heat transfer rates. A momentum thickness Reynolds number based transition criterion analogous to the methodology currently used in flight predictions seems to predict transition onset with reasonable accuracy, although transition was observed to occur later (at higher $\operatorname{Re}_{\theta} / M_{e}$ ) than the current MSL design criterion. However, the utility of the current T5 data for predicting transition on the flight vehicle is questionable because the T5 measurements are of smooth-wall transition rather than on an ablating surface as will exist in flight.

The effects of wall catalysis played an important role in the tests. All of the laminar test data were best modeled assuming that the wall promotes full recombination of all incident species to $\mathrm{CO}_{2}$ (supercatalytic wall). Agreement between the CFD simulations and the laminar data was good as long as this supercatalytic wall model was employed, which establishes a calibration baseline from which the fidelity of the turbulent flow simulations can be established. Interestingly, all turbulent shots were best modeled assuming a nearly noncatalytic surface. Possible reasons for this anomaly, including the choice of turbulent Schmidt number and turbulence model employed, were explored, but did not provide a clear solution. This discrepancy has not been resolved, but appears to be due either to inadequacies in the turbulence models employed for this type of flow or a poor understanding of the actual surface kinetics of stainless steel or chromel-constantan at shock tunnel conditions. Although the flight heat shield will be made of an ablative TPS material rather than stainless steel, a better understanding of the reasons for this discrepancy is important because it will enable us to separate catalytic effects from underlying turbulent heating in these tests, which will improve our understanding of the performance of the turbulence models employed at flight conditions.

\section{Acknowledgments}

Support for this work was provided to NASA Ames and Langley Research Centers by the Mars Technology Program in support of the Mars Science Laboratory mission. The California Institute of Technology was funded by the Jet Propulsion Laboratory under contract No. JPL PO \#1256067. The authors would like to thank Jeff
Umland (Jet Propulsion Laboratory) for his support, as well as Dan Reda (Ames) and Brian Hollis (Langley) for discussions on turbulent transition criteria in flight and ground test facilities.

\section{References}

[1] Martin Marietta Corp., "Viking Lander System Primary Mission Performance Report," NASA, CR-145148, 1977.

[2] Edquist, K. T., Liechty, D. S., Hollis, B. R., Alter, S. J., and Loomis, M., "Aeroheating Environments for a Mars Smart Lander," AIAA Paper 2002-4505, Aug. 2002.

[3] Liechty, D. S., and Hollis, B. R., "Heat Shield Parametric Experimental Aeroheating for a Mars Smart Lander," AIAA Paper 2002-2746, June 2002

[4] Hollis, B. R., and Liechty, D. S., "Boundary Layer Transition Correlations and Aeroheating Predictions for Mars Smart Lander," AIAA Paper 2002-2745, June 2002.

[5] Hollis, B., Leichty, D., Wright, M., Holden, M., Wadhams, T., MacLean, M., and Dyakonov, A., "Transition Onset Correlations and Turbulent Heating Measurements for the Mars Science Laboratory Entry Vehicle,” AIAA Paper 2005-1437, Jan. 2005.

[6] Olejniczak, J., Wright, M. J., Brown, J. L., and Hornung, H., "Computational Modeling of T5 Laminar and Turbulent Heating Data on Blunt Cones, Part 1: Titan Applications," AIAA Paper 2005-0176, Jan. 2005.

[7] Hornung, H. G., Sturtevant, B., Belanger, J., Sanderson, S. R., Brouillette, M., and Jenkins, M., "Performance Data of the New FreePiston Shock Tunnel T5 and GALCIT," Proceedings of the 18th International Symposium on Shock Waves, edited by Takayama, K., Springer-Verlag, Berline, 1992, pp. 603-610.

[8] Wright, M. J., Candler, G. V., and Bose, D., "Data-Parallel Line Relaxation Method for the Navier-Stokes Equations," AIAA Journal, Vol. 36, No. 9, 1998, pp. 1603-1609.

[9] Cheatwood, F. M., and Gnoffo, P. A., "User's Manual for the Langley Aerothermodynamic Upwind Relaxation Algorithm (LAURA)," NASA, TM 4674, April 1996.

[10] MacCormack, R., and Candler, G., "The Solution of the Navier-Stokes Equations Using Gauss-Seidel Line Relaxation," Computers and Fluids, Vol. 17, No. 1, 1989, pp. 135-150.

[11] Yee, H., "A Class of High-Resolution Explicit and Implicit Shock Capturing Methods," NASA, TM 101088, Feb. 1989.

[12] Roe, P. L., "Approximate Riemann Solvers, Parameter Vectors and Difference Schemes," Journal of Computational Physics, Vol. 49, No. 3, 1983, pp. 357-393.

[13] Park, C., Howe, J. T., Jaffe, R. J., and Candler, G. V., "Review of Chemical-Kinetic Problems of Future NASA Missions, II: Mars Entries," Journal of Thermophysics and Heat Transfer, Vol. 8, No. 1, 1994, pp. 9-23.

[14] Park, C., Nonequilibrium Hypersonic Aerothermodynamics, Wiley, New York, 1990.

[15] Millikan, R., and White, D., "Systematics of Vibrational Relaxation," Journal of Chemical Physics, Vol. 39, No. 12, 1963, pp. 3209-3213.

[16] Camac, M., " $\mathrm{CO}_{2}$ Relaxation Processes in Shock Waves," Fundamental Phenomena in Hypersonic Flow, edited by Hall, J. G., Cornell Univ. Press, Ithaca, NY, 1964, pp. 195-215.

[17] Gupta, R., Yos, J., Thompson, R., and Lee, K., "A Review of Reaction Rates and Thermodynamic and Transport Properties for an 11-Species Air Model for Chemical and Thermal Nonequilibrium Calculations to 30,000 K," NASA, RP-1232, Aug. 1990.

[18] Palmer, G. E., and Wright, M. J., "A Comparison of Methods to 
Compute High Temperature Gas Viscosity," Journal of Thermophysics and Heat Transfer, Vol. 17, No. 2, 2003, pp. 232-239.

[19] Palmer, G. E., and Wright, M. J., "A Comparison of Methods to Compute High Temperature Gas Thermal Conductivity," AIAA Paper 2003-3913, June 2003.

[20] Ramshaw, J. D., "Self-Consistent Effective Binary Diffusion in Multicomponent Gas Mixtures," Journal of Non-Equilibrium Thermodynamics, Vol. 15, No. 3, 1990, pp. 295-300.

[21] Sutton, K., and Gnoffo, P. A., "Multi Component Diffusion with Application to Computational Aerothermo-Dynamics," AIAA Paper 98-2575, June 1998.

[22] Baldwin, B., and Lomax, H., "Thin Layer Approximation and Algebraic Model for Separated Turbulent Flows," AIAA Paper 78-257, Jan. 1978.

[23] Menter, F. R., "Two-Equation Eddy-Viscosity Turbulence Models for Engineering Applications," AIAA Journal, Vol. 32, No. 8, 1994, pp. $1598-1605$.

[24] Brown, J. L., "Turbulence Model Validation for Hypersonic Flows," AIAA Paper 2002-3308, June 2002.

[25] Kolesnikov, A., Yakushin, M., Pershin, I., and Vasil'evskii, S., "Heat Transfer Simulation and Surface Catalycity Prediction at the Martian Atmosphere Entry Conditions," AIAA Paper 99-4892, Aug. 1999.

[26] Sepka, S., Chen, Y.-K., Marschall, J., and Copeland, R., "Experimental Investigation of Surface Reactions in Carbon Monoxide and Oxygen Mixtures," Journal of Thermophysics and Heat Transfer, Vol. 14, No. 1, 2000, pp. 45-52.

[27] Afonina, N. E., Gromov, V. G., and Kovalev, V. L., "Catalysis Modeling for Thermal Protection Systems of Vehicles Entering into Martian Atmosphere," AIAA Paper 2001-2832, June 2001.

[28] Rini, P., Garcia, A., Magin, T., and Degrez, G., "Numerical Simulation of $\mathrm{CO}_{2}$ Nonequilibrium Flows with Catalyzed Surface Reactions,"
AIAA Paper 2003-4038, June 2003.

[29] Papadopoulos, P., Prabhu, D., Olynick, D., Chen, Y.-K., and Cheatwood, F. M., "CFD Code Comparisons for Mars Entry Simulations," AIAA Paper 98-0272, Jan. 1998.

[30] Mitcheltree, R., and Gnoffo, P., "Wake Flow About a MESUR Mars Entry Vehicle," AIAA Paper 94-1958, June 1994.

[31] McIntosh, M., "Computer Program for the Numerical Calculation of Frozen and Equilibrium Conditions in Shock Tunnels," Ph.D. Thesis, Australian National Univ., Canberra, Australia, 1971.

[32] Wright, M. J., Olejniczak, J., Brown, J. L., Hornung, H. G., and Edquist, K. T., "Computational Modeling of T5 Laminar and Turbulent Heating Data on Blunt Cones, Part 2: Mars Applications," AIAA Paper 20050177, Jan. 2005.

[33] Bonzel, H. P., and Ku, R., "Carbon Monoxide Oxidation on a Pt(110) Single Crystal Surface," Journal of Vacuum Science and Technology, Vol. 9, No. 2, 1972, pp. 663-667.

[34] Christmann, K., Introduction to Surface Physical Chemistry, SpringerVerlag, New York, 1991.

[35] Kissel-Osterrieder, R., Behrendt, F., Warnatz, J., Metka, U., Volpp, H., and Wolfrum, J., "Experimental and Theoretical Investigation of $\mathrm{CO}$ Oxidation on Platinum: Bridging the Pressure and Materials Gap," Proceedings of the Combustion Institute, Vol. 28, 2000, pp. 13411348.

[36] Nasuti, F., Barbato, M., and Bruno, C., "Material-Dependent Catalytic Recombination Modeling for Hypersonic Flows," Journal of Thermophysics and Heat Transfer, Vol. 10, No. 1, 1996, pp. 131-136.

[37] Kovasznay, L. "The Turbulent Boundary Layer," Annual Review of Fluid Mechanics, Vol. 2, 1970, pp. 95-112.

[38] Reda, D. C., "Review and Synthesis of Roughness-Dominated Transition Correlations for Reentry Applications," Journal of Spacecraft and Rockets, Vol. 39, No. 2, 2002, pp. 161-167. 